American Journal of Immunology 6 (4): 54-61, 2010

ISSN 1553-619X

(C) 2010 Science Publications

\title{
Understand the Role of Natural Killer
}

\author{
${ }^{1}$ Han Yuen Lam, ${ }^{2}$ Swee Keong Yeap, ${ }^{1}$ Noorjahan Banu Alitheen, \\ ${ }^{1}$ Wan Yong Ho, ${ }^{2}$ Abdul Rahman Omar, \\ ${ }^{3}$ Khatijah Yusoff, ${ }^{4} \mathrm{Abd}$ Aziz Suraini and ${ }^{5}$ Huynh Ky \\ ${ }^{1}$ Depterment of Cell and Molecular Biology, \\ Faculty of Biotechnology and Biomolecular Sciences, \\ ${ }^{2}$ Institute of Bioscience, \\ ${ }^{3}$ Depterment of Microbiology, \\ Faculty of Biotechnology and Biomolecular Sciences, \\ ${ }^{4}$ Deptermernt of Bioprocess Technology, \\ Faculty of Biotechnology and Biomolecular Sciences, \\ University Putra Malaysia, 43400, Serdang, Selangor, Malaysia \\ ${ }^{5}$ Department of Agriculture Genetics and Breeding, \\ College of Agriculture and Applied Biology, \\ Cantho University, Cantho City, Vietnam
}

\begin{abstract}
Problem statement: Immunosuppression is a common approach for pathogens or cancer to escape from immune system of the infected host. Some of the antimicrobe or anticancer drugs may also weaken the body immune system. Among various types of immune cell, natural killer cells are the key component of the innate immunity which plays an important role in first line defense against cancer and microbe infections. Thus, understand the role of Natural killer cell can help to design a successful natural killer cell base therapy in cancer and infectious disease therapy. Approach: Natural killer cell unik activation/inhibition ligand, cytolytic granules and proinflammatory cytokiens offered a specific killing mechanism toward cancer or infected cell target. These specific activation can be achieved in the present of immunomodulator such as cytokines (IL-2 and IL-12) or mitogens (plant extract such as Rhaphidophora korthalsii methanol extract). Results: Key rule of Natural killer cell base immunotherapy is to maintain enough activated Natural killer cell number in the infected host. Conclusion/Recommendations: Future study should expand the clinical use of in vivo or ex-vivo Natural killer cell base therapy especially in cancer treatment.
\end{abstract}

Key words: Peripheral blood mononuclear cell, Natural Killer (NK), Caspase-Activated DNase (CAD), immunological memory, Lymphokine Activated Killer (LAK), Cytotoxic T Cells (CTL), condition may happen

\section{INTRODUCTION}

Immune system is a network of cells, tissues and organs which work closely to defend the body from diseases through identifying and removing pathogens and tumour cells. Thus, human health is always related to immune responses (National Institutes of Health, 2003). The immune system can be grouped based on their functions. The classes of immune system are innate (or natural) immunity and acquired immunity (adaptive immunity) (Yeap et al., 2007). Innate immunity is the non-specific first line body defense which provides immediate response to infection penetrating the body physical barriers (Litman et al., 2005). On the other hand, pathogen specific acquired immunity is a third layer of protection activated by the innate immunity. It improves the recognition and elimination of pathogen through discrimination of selfand non-self antigens and also development of immunological memory. Acquired immunity can be separated into two components which are cell-mediated immunity or humoral immunity. Cell mediated immunity is an immune response which involves the activation of lymphocytes such as macrophages, Natural Killer (NK) cells and T cells but do not involve the antibodies or complements which are mainly

Corresponding Author: Swee Keong Yeap, Institute of Bioscience, University Putra Malaysia, 43400, Serdang, Selangor, Malaysia Tel: +60389467471 Fax:+60389467510 
produced by the B cells. Since immunosuppression is a common phenomena during progression of certain diseases such as cancer, ex-vivo cell base adoptive tumour immunotherapy using Lymphokine Activated Killer (LAK) cell as the effector cells to maintain patients' immune system besides targeting the cancer cell have been proposed as the potential cancer treatment (Suck, 2006). LAK cells is a mixture population of killer cells including natural killer (NK) $\left(\mathrm{CD}^{-} / \mathrm{CD}^{+} 6^{+}\right), \quad$ cytolytic $\quad$ NK-T $\quad$ (CNK-T) $\left(\mathrm{CD}^{+} / \mathrm{CD}^{+} 6^{+}\right), \quad$ Cytokine-Induced Killer (CIK) $\left(\mathrm{CD}^{+} / \mathrm{CD}^{+} 6^{+}\right.$), and Cytotoxic T Lymphocytes (CTL) $\left(\mathrm{CD}^{+} / \mathrm{CD}^{+}\right)$which could lyse a broad range of fresh and cultured tumour cells (Ozdemir and Savasan, 2005). It is generated by activating the Peripheral Blood Mononuclear Cells (PBMC) isolated from the cancer microenvironment (commonly known as tumor infiltrated lymphocytes) with the cytokine [especially interleukin 2 (IL-2)]. Generally, PBMC are critical to fight infections or any invaders. Many studies have shown that human PBMC functions can be stimulated or inhibited by immunomodulatory agents. Huang et al. (1995) described that PBMC pre-treated with immunomodulators, such as cytokines, either in vitro or in vivo manner, might increase anti-viral activity. Besides, influenza A virus induced PBMC displayed strong cytotoxicity against melanoma cells, if compared to the non-treated cells (Sturlan et al., 2009). This cytotoxic effect depends on the cellular contact between PBMC and target cells, as well as the cytokines secreted, such as TNF, IL-6 and IFN. This adoptive immunotherapy is a passive immunization involving the transplantation of immune effector cells to kill tumour cells. However, low efficiency and toxic side effects was often couple with this type of treatment. The low success rate of adoptive immunotherapy may be due to low cytolytic activity of the patients' NK cells and the small population of NK cells (approximately 10\%) in the activated LAK (Suck, 2006). Thus, activating the isolated NK cells may improve the efficacy of this adoptive immunotherapy.

Natural killer cell: Natural Killer (NK) cell is a class of large granular lymphocyte that is crucial for innate immune system and involved in a variety of biological processes, including antitumor activity and defense against viral, bacterial, and fungal infections, without any antigenic specificity (Biron et al., 1999; GarciaPenarrubia et al., 1989; Arase et al., 1995; Auernhammer and Melmed, 2000). NK cell function abnormalities are associated with viral infections (OjoAmaize et al., 1994). NK cells are called "natural" because they do not need to recognize any specific antigen to respond and take actions. And, they do not require activation in order to kill target cells that lack of the MHC class I antigens, like tumor cells and virus infected cells. Human NK cells comprise of about 5$20 \%$ of peripheral blood lymphocytes (Cooper et al., 2001a).

In fact, NK cells are derived from human primitive progenitors. Differentiation of NK cells from progenitors requires interaction of primitive-acting ligands (c-kit ligands and Flt3 ligands), as well as cytokines (IL-2, IL-3, IL-7, IL-10, IL-15 and others) (Cooper et al., 2001b; Miller and McCullar, 2001). All human NK cells express CD56 on the surface. The density of surface expression of CD56 can be used to classify functionally and developmentally distinct NK cell subsets. Minority (about 10\%) of human NK cells are CD56 $6^{\text {bright }}$ CD16 ${ }^{\text {dim }} \mathrm{NK}$ cells, which mediate low or no cytotoxicity, but produce high levels of inflammatory cytokines; while majority are $\mathrm{CD} 56^{\mathrm{dim}} \mathrm{CD} 16^{\text {bright }}$ cells that are potent mediators of cytotoxicity (Cooper et al., 2001a; Caliguiri, 2008) as shown in Fig. 1.

Nowadays, numbers of NK cell lines are available that have eased the maintenance and expansion in culture. For example, stable IL-2 producing derivatives of NK-92 cell lines and KHYG-1 cell lines. In the absent of IL-2, NK cell lines maintain their cytotoxicity, as the cells manage to activate immune cells and eliminate disease effectively (Yan et al., 1998). In vitro and in vivo studies demonstrated that NK-92 cells and KHYG-1 can kill half of newly diagnosed and relapsed acute myelogenous leukemias, $\mathrm{T}$ cell adult lymphocytic leukemias, blineage acute lymphocytic leukemias, and chronic myelogenous leukemias (Yan et al., 1998; Suck et al., 2005). Preliminary study showed that intravenous administration of NK-92 cells is safe and the cells are not rejected by the immune system (Reid et al., 2002).

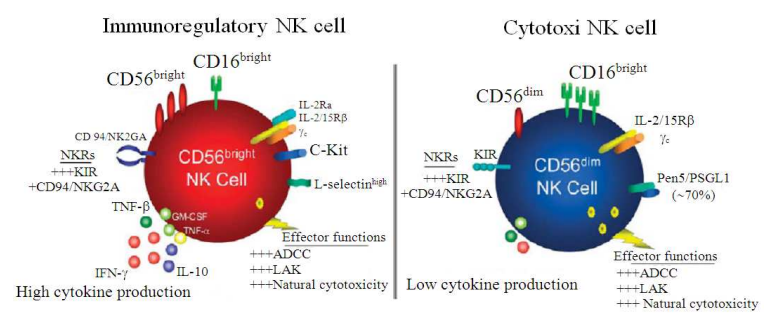

Fig. 1: Human NK cell subsets. The CD56 ${ }^{\text {bright }}$ CD16 ${ }^{\text {dim }}$ NK cells are immunoregulatory cells that secrete high levels of cytokines with low natural cytotoxicity. The CD56 ${ }^{\mathrm{dim}} \mathrm{CD} 16^{\text {bright }} \mathrm{NK}$ cells are cytotoxic cells which produce low levels of cytokines (Farag and Caligiuri, 2006) 
Natural killer cells reacted in different pathways: Human Natural Killer (NK) cell activities are tightly regulated. NK cells possess two types of surface receptors, which are activating receptors and inhibitory receptors. The inhibitory and activating function is determined by the length of associated cytoplasmic tail, either Long (L) or Short (S), respectively (Uhrberg et al., 1997). Balance between inhibitory and activating signals may affect immune responses. Inhibitory receptors recognize MHC class I molecules that are normally expressed on the surface of normal cells to protect from autoimmune disease. Therefore, NK cells are able to kill target cells possessing low or absent of MHC class I molecules. NK cells response to kill the targets in two different mechanisms, either by cytotoxic granule exocytosis or by induction of death receptor-mediated apoptosis.

Granule mediated cytolytic pathway: Granule mediated cytolytic mechanism involved the granules presented in $\mathrm{CD}^{+}$Cytolytic $\mathrm{T}$ Lymphocytes (CTL), CD8 ${ }^{+}$CTL, T cells and NK cells. Upon exocytosis of the granules, perforin changes its conformation, polymerizes into tube-like structure (polyperforins) and inserts into the membrane, in the presence of calcium ions (Masson and Tschopp, 1985). Transmembrane channels are generated; as a result, the target cells lose membrane integrity and appear to die by osmotic lysis (Liu et al., 1995). Besides, granzymes diffuse to the cytosol by endosomal pathway, further activates cysteine proteases, which in turn cleave structural and regulatory proteins, and leads to apoptosis. Granzyme B caused DNA fragmentation in target cells through activating a nuclease called as Caspase-Activated Dnase (Cad) (Fan and Zhang, 2005). Recent reports showed that granzyme B deliver to target cells through electrostatic interactions, further undergo electrostatic exchange from serglycin to target cells (Raja et al., 2005; Shi et al., 2005). Generally, both perforin and granzyme B are acting synergistically. Nevertheless, without granzyme B, exposure of perforin is effectively lysing certain target cells, but cannot induce DNA fragmentation (Duke et al., 1989). In contrast, in the absent of perforin, granzyme B could induce apoptosis in target cells via endocytosis (Spaeny-Dekking et al., 1998). This suggested that granzyme B played more important role in mediating granule-mediated cytotoxicity.

Fas ligand and Trail pathway: Natural Killer (NK) cells demonstrated another cytolytic mechanism through the induction of death receptor-mediated apoptosis (Smyth et al., 2002). These death ligands belong to the Tumor Necrosis Factor (TNF) family of ligands, comprise of a large family, included TNF- $\alpha$, Fas ligands (FasL), CD40L, lymphotoxin $\alpha$ (LT $\alpha$ ) and LT $\beta$, Receptor Activator of Nuclear Factor-Kappa B Ligands (RANKL) as well as TNF-Related ApoptosisInducing Ligands (TRAIL) (Mirandola et al., 2004).

Activation of NK cells have been linked to the expression of several death receptors, such as FasL (CD95) and TRAIL. Binding of Fas ligands of target cells with Fas receptors on NK cells induces cytotoxicity (1995). Another type of death receptor, TRAIL can bind to the death receptors DR4 (TRAILRI) and DR5 (TRAIL-RII) and induces apoptosis of target cells. Takeda et al. ( 2001) reported that TRAIL sensitive tumor cells proliferated, in the presence of neutralizing anti-TRAIL antibody against TRAIL transfected effector cells; but this not happens to TRAIL resistance tumor cells. Administration of antiTRAIL antibody to NK cell depleted, interferondeficient, TRAIL-sensitive tumor injected mice, also resulted in greater metastasis (Takeda et al., 2001). However, this cell death pathway must happen in cell to cell direct contact manner.

Besides the death ligands, a large family of secreted cytokines of TNF family, that are pleiotropic, such as Nitride Oxide (NO), also mediate apoptosis (Cifone et al., 1999; Kwak et al., 2000).

Cytokines involved in activation of immune system: Cytokines are small proteins secreted by specific cells of the immune system that characterized by considerable redundancy and pleiotropism. They acted as immunomodulator to regulate immune system functions, such as proliferation, cell survival or death, differentiation and various gene expressions (Street $e$ t al., 2001). They also involved in development processes during embryogenesis. Some cytokines circulate in picomolar $\left(10^{-12} \mathrm{M}\right)$ concentrations, but able to increase up to 1000 fold, upon stimulation. Natural Killer (NK) cells secrete a lot of functional cytokines, such as IFN$\gamma$, TNF, GM-CSF, IL-5, IL-10, IL-13 and more (Cooper et al., 2001b; Smyth et al., 2002).

Interferon-gamma (IFN- $\gamma)$ is the hallmark cytokine of $\mathrm{T}_{\mathrm{H}} 1$ cells. In fact, CD56 $6^{\text {bright }} \mathrm{CD} 16^{\text {dim }} \mathrm{NK}$ cells are the primary source of IFN- $\gamma$ when the cells are being stimulated (Cooper et al., 2001b). CD8 ${ }^{+}$ Cytotoxic T Cells (CTL) and Natural Killer T (NKT) cells also produce IFN- $\gamma$. IFN- $\gamma$ is well known with its immunoregulatory and anti-tumor properties (Street et al., 2001). It triggers of pro-inflammatory cascade that causes increasing of antigen presentation, promotes adhesion and binding required for leukocyte migration, as well as 
activation of $\mathrm{T}$ cell, NK cell and the macrophages lysosome activity (Nathan et al., 1983; Winkler et al., 2006). In addition, IFN- $\gamma$ can up-regulate expression of MHC class I molecules and thus, increase the sensitivity of tumor cells to Fas ligands (FasL) mediated cytotoxicity.

Interleukin-2 (IL-2) is a multifunctional inflammatory cytokine which activates the immune system by cells proliferation, cytokines production and Lymphokine Activated Killer (LAK) cell generation (Hughes, 1998; Zhang, et al., 2008). Instead, IL-2 is identified as a T-cell growth factor that regulates $\mathrm{T}$ cell proliferation and maturation (Conrad, 2003). Besides, IL-2 can augment cytotoxic activity by enhancing the target immunogenicity (Bradley et al., 1998). Nowadays, IL-2 is approved by the U.S. Food and Drug Administration (FDA) for the treatment of metastatic renal cell carcinoma and melanoma. High dosage of IL-2 was commonly used to treat metastasis (Dutcher, 2002). However, severe toxicities were developed in most patients, such as hypotension, lack of appetite, and fever. Phase II trial of subcutaneous injection of recombinant IL-2 in advanced cutaneous $\mathrm{T}$ cell lymphoma resulted in expansion of $\mathrm{T}$ cells, but caused toxic side effects and less efficiency. Majority patients suffered with grade 1 or 2 in severity; and one patient developed grade 4 lymphopenia. To limit the toxicities, lower administration dosage or combination of IL-2 with other targeted agents may be the solutions for cancer patients (Querfeld et al., 2007).

Interleukin 12 (IL-12) is a T cell stimulating factor, originally produced by dendritic cells, macrophages and B-lymphoblastoid cells (NC-37) in response to antigenic stimulation. IL-12 augments cytotoxic activity of $\mathrm{NK}$ cells and $\mathrm{CD}^{+}$CTL by stimulating the production of IFN- $\gamma$, further enhances $T_{H} 1$ immune responses, includes cellular immunity and production of antibodies (Fehniger et al., 1999; Tripp et al., 1993). Thus, IL-12 possesses anti-inflammation and antiangiogenesis activities, associated with IFN- $\gamma$ production (Stone et al., 2003). Brunda et al. (1993) reported in vivo antitumor activity was displayed by IL12 , without any gross toxicity. However, in phase I trial on patients, the clinical testing abruptly curtailed due to unexpected severe toxicities, although antitumor effect was obtained (Atkins et al., 1997).

Cytotoxic and cytolysis: Cytotoxic is referring to the substances that are toxic to cells or caused cells death. Since 1950s, many scientists have focused on the application of cytotoxic agents in anticancer study and encouraging results had been obtained (Kennedy, 1991).
In contrast, cytolysis is relating to an important immune function of cell dissolution or destruction. Cytolysis process involved cytolytic cells that are able to lyses a broad range of cells, especially tumor cells and virusinduced cells. The cytolysis effect towards the target cells can be augmented when an immunomodulatory agent was administered to the immune cells (Yeap et al., 2007; Lafleur et al., 2001; Yeap et al., 2011).

Antimicrobial property of NK cell: Natural Killer (NK) cells function as a key factor in immediate immune responses to virus infection and intracellular infections of mycobacterial and bacterial (Orange, 2002; Salazar-Mather et al., 1998; Unanue, 1997). A patient with complete lacking of NK cells would sustain severe virus and other fungal infection. NK cells are populations of lymphocytes that can be activated to mediate significant levels of cytotoxic activity and produce high levels of certain cytokines, such as IFN- $\gamma$. NK cell-derived IFN- $\gamma$ leads to $\mathrm{T}_{\mathrm{H}} 1$-type immunity and activates macrophages, resulting in production of IFN$\alpha$, IL-12 and IL-18 (Biron et al., 1999). IFN- $\gamma$ limits transynaptic transmission, prevent viral reactivation and inhibit virus-induced apoptosis (Cantin et al., 1999; Geiger et al., 1995; Mikloska and Cunningham, 2001). In addition, MHC class I expression of viruses-infected cells are often being suppressed; hence, the infected cells become more susceptible to killing by NK cells. Activation of NK cell-mediated cytotoxicity would occur during viral infections, including arenaviruses, herpesviruses, Herpes Simplex Virus (HSV), influenza virus, Coxsackie virus and more (Biron et al., 1999). Salazar-Mather (1998) reported that IFN- $\gamma$ production was enhanced upon stimulation by influenza virus and murine cytomegalovirus (MCMV). NK cells also exhibit antiviral activity through antibody dependent cellmediated cytotoxicity (ADCC) mechanism.

Antitumor property of NK cell: Natural Killer (NK) cells are cytotoxic cells and capable to mediate spontaneous cytotoxicity against tumor cells and bloodborne metastasis (Vujanovic et al., 1996; Whiteside and Herberman, 1995) In fact, most of the cancer cells have reduced or no MHC class I expression; hence, become susceptible to killing by $\mathrm{NK}$ cells (Ljunggren and Karre, 1985). Zhang et al. (2008) showed that a number of cytokines produced, such as IL-2, IL-15 and IL-12, can enhance cytotoxic activity of NK cells. Moreover, production of interferon may augment NK cytotoxic activity. NK cell-mediated cytolysis is largely mediated by perforin and granzyme B as well as the death ligands of TNF family. 
Unfortunately, NK cells therapy has limited efficacy, even though it may induce tumor regression in some cases. Therefore, intratumoral injection of tumor vaccine in combination of adjuvant, such as IL-2, may help in NK cells activation, and trigger tumor regression response (Ishikawa et al., 2004). Added to this, not all types of cancer are suitable with the magic bullet IL-2 plus NK cell. Kim et al. (2004) has reported that hepatoblastoma cell was only susceptible to IL-2 activated NK cell granule-dependent necrotic death. Thus, this combination that induced necrosis which may further promote the cancer cell metastasis are not suitable for this hepatoblastoma immunotherapy. Due to this disadvantage of using cytokine to activate $\mathrm{NK}$ cell for tumor immunotherapy, attempt to search for NK cell immunomodulator from natural source is one of the current focus for the field of immunology. Yeap et al. (2011; 2007) have proved that Rhaphidophora korthalsii methanol extract was able to target hepatoblastoma and myelogenous leukaemia cell death via apoptosis. Effort to understand the mechanism of NK cell activation and the cytolytic process induced by the extract activated NK cell against the cancer target are still going on.

\section{CONCLUSION}

Although LAK cell generated from PBMC using recombinant IL-2 as a immunomodulator demonstrated the potential as effective killer cell in cancer immunotherapy, isolating the NK cell which was the most important player in LAK cell may be able to enhance the specificity and efficiency of that treatment. Furthermore, NK cell in the present of IL2 cannot be treated as the magic bullet against all type of immunosuppressive disease since it may induce necrosis rather than apoptosis against the specific target cell. Thus, continuous effort on searching potential immunomodulators from various natural sources (Yeap et al., 2011; 2007) and combination of cytokines (Capitini et al., 2009) to activate NK cell cytolytic activity for different purpose may be a safe and warrant solution for different type of diseases. Caution needs to be work out to monitor the sensitivity of the patients against this NK cell base treatment since autoimmunity which complicate the patients' condition may happen.

\section{REFERENCES}

Arase, H., N. Arase and T. Saito, 1995. Fas-mediated cytotoxicity by freshly isolated natural killer cells. J. Exp. Med., 181: 1235-1238. jem.rupress.org/content/181/3/1235.full.pdf
Atkins, M.B., M.J. Robertson, M. Gordon, M.T. Lotze and M. Decoste, et al., 1997. Phase I evaluation of intravenous recombinant human interleukin 12 in patients with advanced malignancies. Clin. Cancer Res., 3: 409-417. PMID: 9815699

Auernhammer, C.J. and S. Melmed, 2000. Leukemiainhibitory factor-neuroimmune modulator of endocrine function. Endocrine Rev., 21: 313-345. DOI: 10.1210 /er.21.3.313

Biron, C.A., K.B. Nguyen, G.C. Pien, L.P. Cousens and T.P. Salazar-Mather, 1999. Natural killer cells in antiviral defense: Function and regulation by innate cytokines. Ann. Rev. Immunology, 17: 189-220. PMID: 10358757

Bradley, M., A. Zeytun, A. Rafi-Janajreh, P.S. Nagarkatti and M. Nagarkatti, 1998. Role of spontaneous and interleukin-2-induced natural killer cell activity in the cytotoxicity and rejection of $\mathrm{Fas}^{+}$and Fas ${ }^{-}$tumor cells. Blood, 92: 4248-4255. http://lib.bioinfo.pl/paper:9834230

Brunda, M.J., L. Luistro, R.R. Warrier, R.B. Wright and B.R. Hubbard et al., 1993. Antitumor and antimetastatic activity of interleukin 12 against murine tumors. J. Exp. Med., 178: 1223-1230. PMID: 8104230

Caliguiri, M.A., 2008. Human natural killer cells. Blood, 112: 461-469. DOI: 10.1182/blood-200709-077438

Cantin, E., B. Tanamachi and H. Openshaw, 1999. Role of gamma interferon in control of herpes simplex virus type 1 reactivation. J. Virol., 73: 3418-3423. jvi.asm.org/cgi/content/full/73/4/3418

Capitini, C.M, T.J. Fry, C.L. Mackall, 2009. Cytokines as adjuvants for vaccine and cellular therapies for cancer. Am. J. Imm., 5: 65-83. DOI: 10.3844/ajisp.2009.65.83

Cifone, M.G., S.D. Alo, R. Parroni, D. Millimaggi and L. Biordi et al., 1999. Interleukin-2 activated rat natural killer cells express inducible nitric oxide synthase that contributes to cytotoxic function and interferon- $\gamma$ production. Blood, 93: 3876-3884. PMID: 10339496

Conrad, A., 2003. Interleukin-2-where are we going? J. Association Nurses AIDS Care, 14: 83-88. PMID: 14682072

Cooper, M.A., T.A. Fehniger and M.A. Caligiuri, 2001a. The biology of human natural killer-cell subsets. Trends Immunology, 22: 633-640. PMID: 11698225

Cooper, M.A., T.A. Fehniger, S.C. Turner, K.C. Chen and B.A. Ghaheri, et al., 2001b. Human natural killer cells: A unique innate immunoregulatory role for the CD56 ${ }^{\text {bright }}$ subset. Blood, 97: 3146-3151. PMID: 11342442 
Duke, R.C., P.M. Persechini, S. Chang, C.C. Liu and J. Cohen et al., 1989. Purified perforin induces target cell lysis but not DNA fragmentation. J. Exp. Med., 170: 1451-1456. jem.rupress.org/content/170/4/1451.full.pdf

Dutcher, J., 2002. Current status of interleukin-2 therapy for metastatic renal cell carcinoma and metastatic melanoma. Oncology, 16: 4-10. PMID: 8717513

Fan, Z. and Q. Zhang, 2005. Molecular mechanisms of lymphocyte-mediated cytotoxicity. Cellular Molecular Immunol., 2: 259-264. PMID: 8717513

Farag, S.S. and M.A. Caligiuri, 2006. Human natural killer cell development and biology. Blood Reviews, 20, 123-137. PMID: 16364519

Fehniger, T.A., M.H. Shah, M.J. Turner, J. VanDeusenn and S.P. Whitman, et al., 1999. Differential cytokine and chemokine gene expression by human NK cells following activation with IL-18 or Il-15 in combination with IL-12: implications for the innate immunity response. The J. Immunol., 162: 4511-4520. PMID: 10201989

Garcia-Penarrubia, P., A.D. Bankhurst and F.T. Koster, 1989. Prostaglandins from human $\mathrm{T}$ suppressor/cytotoxic cells modulate natural killer antibacterial activity. The J. Exper. Med., 170: 601-606. jem.rupress.org/content/170/2/601.full.pdf+html

Geiger, K.D., D. Gurushanthaiah, E.L. Howest, G.A. Lewandowski and J.C. Reed, et al., 1995. Cytokine-mediated survival from lethal herpes simplex virus infection: role of programmed neuronal death. Proc. National Acad. Sci., 92: 3411-3415. www.jstor.org/stable/2367076

Huang, X.L., Z. Fan, T. Murayama and C. Rinaldo, 1995. Enhancement of natural killer cell activity in human immunodefiency virus-infected subjects by in vitro treatment with biologic response modifier OK-432. Clinical Diagnosis Laboratory Immunology, 2: 91-97. www.ncbi.nlm.nih.gov/pmc/articles/PMC170107/p df/020091.pdf

Hughes, H.P.A., 1998. Cytokine adjuvants: Lessons from the past-guidelines for the future? Vet. Immunol. Immunopathol., 63: 131-138. DOI: 10.1016/S0165-2427(98)00089-0

Ishikawa, E., K. Tsuboi, S. Takano, E. Uchimura and T. Nose et al., 2004. Intratumoral injection of IL-2activated NK cells enhances the antitumor effect of intradermally injected paraformaldehyde-fixed tumor vaccine in a rat intracranial brain tumor model. Cancer Science, 95: 98-103. PMID: 14720334
Kennedy, B.J., 1991. Evolution of chemotherapy. CA. A Cancer J. Clin., 41: 261-263. onlinelibrary.wiley.com/doi/10.3322/canjclin.41.5. 261/pdf

Kim, H.R., H.J. Park, J.H. Park, S.J. Kim and K.H. Kim, et al., 2004. Characteristics of the killing mechanism of human natural killer cells against hepatocellular carcinoma cell lines HepG2 and Hep3B. Cancer Immunol. Immunotherapy, 52: 461-470.

www.springerlink.com/index/JX2TR7UDHYQTA VA0.pdf

Kwak, J.Y., M.K. Han, K.S. Choi, I.H. Park and S.Y. Park et al., 2000. Cytokines secreted by lymphokine-activated killer cells induce endogenous nitric oxide synthesis and apoptosis in DLD-1 colon cancer cells. Cellular Immunol., 203: 84-94. DOI: 10.1006/CIMM.2000.1682

Lafleur, R.L., C. Malazdrewich, S. Jeyaseelan, E. Bleifield and M.S. Abrahamsen et al., 2001. Lipopolysaccharide enhances cytolysis and inflammatory cytokine induction in bovine alveolar macrophages exposed to Pasteurell (Mannheimia) haemolytica leukotoxin. Microbial Pathogenesis, 30: 347-357. DOI: 10.1006/MPAT.2000.0438

Litman, G.W., J.P. Cannon and L.J. Dishaw, 2005. Reconstructing immune phylogeny: new perspectives. Nat. Rev. Immunol., 5: 866-879. PMID: 16261174

Liu, C.C., C.M. Walsh and J.D.E. Young, 1995. Perforin: Structure and function. Immunology Today, 16: 194-201. PMID: 7734048

Ljunggren, H.G. and K. Karre, 1985. Host resistance directed selectively against H-2-deficient lymphoma variants. J. Exp. Med., 162: 1745-1759. PMID: 3877776

Masson, D. and J. Tschopp, 1985. Isolation of lytic, pore-forming protein (perforin) from cytolytic Tlymphocytes. J. Biol. Chem., 260: 9069-9072. www.jbc.org/content/260/16/9069.full.pdf+html

Mikloska, Z. and A.L. Cunningham, 2001. Alpha and gamma interferons inhibit herpes simplex virus type 1 infection and spread in epidermal cells after axonal transmission. J. Virol., 75: 11821-11826. PMID: 11689663

Miller, J.S. and V. McCullar, 2001. Human natural killer cells with polyclonal lectin and immunoglobulinlike receptors develop from ingle hematopoietic stem cells with preferential expression of NKG2A and KIR2DL2/L3/S2. Blood, 98: 705-713. bloodjournal.hematologylibrary.org/content/98/3/7 05.full.pdf 
Mirandola, P., C. Ponti, G. Gobbi, I. Sponzilli and M. Vaccarezza et al., 2004. Activated human NK and $\mathrm{CD}^{+} \mathrm{T}$ cells express both TNF-related apoptosisinducing ligand (TRAIL) and TRAIL receptors but are resistant to TRAIL-mediated cytotoxicity. Blood, 104: 2418-2424. PMID: 15205263

Nathan, C.F., H.W. Murray, M.E. Wiebe and B.Y. Rubin, 1983. Identification of interferon- $\gamma$ as the lymphokine that activates human macrophage oxidative metabolism and antimicrobial activity. J. Exp. Med., 158: 670-689. PMID: 6411853

National Institutes of Health, 2003. Understanding the immune system. How it works. Retrieve 5-1, 2009 from

http://www.niaid.nih.gov/Publications/immune/the _immune_system.pdf

Ojo-Amaize, E.A., E.J. Conley and J.B. Peter, 1994. Decreased natural killer cell activity is associated with severity of chronic fatigue immune dysfunction syndrome. Clin. Infect. Dis., 18: 157159. PMID: 8148445

Orange, J.S., 2002. Human natural killer cell deficiency and susceptibility to infection. Microbes Infect., 4: 1545-1558. PMID: 12505527

Ozdemir, O. and S. Savasan, 2005. Combinational IL2/IL-15 induction does not further enhance IL-15induced lymphokine-activated killer cell cytotoxicity against human leukemia/lymphoma cells. Clin. Immunol., 115: 240-249. PMID: 15893691

Querfeld, C., S.T. Rosen, J. Guitart, A. Rademaker and F. Foss et al., 2007. Phase II trial of subcutaneous injections of human recombinant interleukin-2 or the treatment of mycosis fungoides and Sezary syndrome. J. Am. Acad. Dermatol., 56: 580-583. PMID: 17367611

Raja, S.M., S.S. Metkar, S. Honing, B. Wang and W.A. Russin et al., 2005. A novel mechanism for protein delivery: Granzyme B undergoes electrostatic exchange from serglycin to target cells. J. Biol. Chem., 280: 20752-20761. PMID: 15788411

Reid, G.S.D., S. Bharya, H.G. Klingemann and K.R. Schultz, 2002. Differential killing of pre-B acute lymphoblastic leukaemia cells by activated $\mathrm{Nk}$ cells and the NK-92 ci cell line. Clinical Exp. Immunol., 129: 265-271. PMID: 12165082

Salazar-Mather, T., J.S. Orange and C.A. Biron, 1998. Early Murine Cytomegalovirus (MCMV) infection induces liver Natural Killer (NK) cell inflammation and protection through Macrophage Inflammatory Protein $1 \alpha$ (MIP-1 $\alpha)$-dependent pathways. J. Exp.
Med.,

187: $1-14$. jem.rupress.org/content/187/1/1.full.pdf

Shi, L., D. Keefe, E. Durand, H. Feng and D. Zhang et al., 2005. Granzyme B binds to target cells mostly by charge and must be added at the same time as perforin to trigger apoptosis. J. Immunol., 174: 5456-5461. PMID: 15843543

Smyth, M.J., Y. Hayakawa, K. Takeda and H. Yagita, 2002. New aspects of natural killer-cell surveillance and therapy of cancer. Cancer, 2: 850861. DOI: $10.1038 / \mathrm{nrc} 928$

Spaeny-Dekking, E.H.A., W.L. Hanna, A.M. Wolbink, P.C. Wever and A.J. Kummer et al., 1998. Extracellular Granzymes A and B in humans: Detection of native species during CTL responses in vitro and in vivo. J. Immunol., 160: 3610-3616. PMID: 9531325

Stone, A.E.S., S. Giguere and W.L. Castleman, 2003. IL-2 reduces the severity of Sendai virus-induced bronchiolar inflammatiom and remodeling. Cytokine, 24: 103-113. DOI: 10.1016/J.CYTO.2003.07.005

Street, S.E.A., E.A.D. Cretney and M.J. Smyth, 2001. Perforin and interferon- $\gamma$ activities independently control tumor initiation, growth and metastases. Blood, 97: 192-197. PMID: 11133760

Sturlan, S., M. Sachet, S. Baumann, I. Kuznetsova and A. Spittler et al., 2009. Influenza A virus induces an immediate cytotoxic activity in all major subsets of peripheral blood mononuclear cells. PLoS ONE, 4: e4122. PMID: 19125202

Suck, G., 2006. Novel approaches using natural killer cells in cancer therapy. Semin. Cancer Biol., 16: 412-418. PMID: 16914327

Suck, G., D.R. Branch, M.J. Smyth, R.G. Miller and J. Vergidis, et al., 2005. KHYG-1, a model for the study of enhanced natural killer cell cytotoxicity. Exp. Hematol., 33: 1160-1171. PMID: 16219538

Takeda, K., M.J. Smyth, E. Cretney, Y. Hayakawa and N. Yamaguchi et al., 2001. Involvement of tumor necrosis factor related apoptosis-inducing ligand in NK cell-mediated and IFN- $\gamma$-dependent suppression of subcutaneous tumor growth. Cellular Immunol., 214: 194-200. DOI: 10.1006/CIMM.2001.1896

Tripp, C.S., F.W. Stanley and E.R. Unanue, 1993. Interleukin 12 and tumor necrosis factor $\alpha$ are costimulators of interferon $\gamma$ production by natural killer cells in severe combined immunodeficiency mice with listeriosis, and interleukin 10 is a physiologic antagonist. Proc. Natl. Acad. Sci., 90: 3725-3729. PMID: 8097322 
Uhrberg, M., N.M. Valiante, B.P. Shum, H.G. Shilling and K. Lienert-Weidenbach, et al., 1997. Human diversity in killer cell inhibitory receptor genes. Immunity, 7: 753-763. PMID: 9430221

Unanue, E.R., 1997. Inter-relationship among macrophages, natural killer cells and neutrophils in early stages of Listeria resistance. Curr. Opin. Immunol., 9: 35-43. PMID: 9039774

Vujanovic, N.L., P. Basse, R.B. Herberman and T.L. Whiteside, 1996. Antitumor functions of natural killer cells and controls of metastases. Methods, 9: 394-408. PMID: 8812692

Whiteside, T.L. and R.B. Herberman, 1995. The role of natural killer cells in immune surveillance of cancer. Curr. Opin. Immunol., 7: 704-710. PMID: 8573315

Winkler, C., B. Frick, K. Schroecksnadel, H. Schennach and D. Fuchs, 2006. Food preservatives sodium sulfite and sorbic acid suppress mitogenstimulated peripheral blood mononuclear cells. Food Chem. Toxicol., 44: 2003-2007. DOI: 10.1016/J.FCT.2006.06.019
Yan, Y., P. Steinherz, H.G. Klingemann, D. Dennig and B.H. Childs et al., 1998. Antileukemia activity of a natural killer cell line against human leukemias. Clin. Cancer Res., 4: 2859-2868. PMID: 9829753

Yeap, S.K., N.B. Alitheen, A.M. Ali, A.R. Omar and A.R. Raha, et al., 2007. Effect of Rhaphidophora korthalsii methanol extract on human peripheral blood mononuclear cell proliferation and cytolytic activity toward HepG2. J. Ethnopharmacol., 114: 406-411. DOI: 10.1016/J.JEP.2007.08.020

Yeap, S.K., N.B.M. Alitheen, W.Y. Ho, A.R. Omar and A.M. Ali, et al., 2011. Immunomodulatory role of Rhaphidophora korthalsii methanol extract on human peripheral blood mononuclear cell proliferation, cytokine secretion and cytolytic activity. J. Med. Plant Res., 5: 958-965. http://www.academicjournals.org/jmpr/PDF/pdf20 11/18Mar/Yeap\%20et\%20al.pdf

Zhang, B., J. Zhang and Z.G. Tian, 2008. Comparison in the effects of IL-2, IL-12, IL-15 and IFN $\alpha$ on gene regulation of granzymes of human NK cell line NK-92. Int. Immunopharmacol., 8: 989-996. DOI: 10.1016/J.INTIMP.2008.03.001 